GALVES, Charlotte. 2001. Ensaios sobre as gramáticas do português. Campinas, SP: Editora da Unicamp, 280pp.

Resenhado por/by: João COSTA (Universidade Nova de Lisboa)

Palavras-chave: Clíticos; Topicalização; Movimento do verbo Key-words: Clitics; Topicalization; Verb movement

\title{
Apreciação global
}

A obra Ensaios sobre as gramáticas do português, de Charlotte Galves, consiste numa compilação dos vários artigos que a linguista produziu entre 1983 e 1987. Este livro é de extrema utilidade para todos os linguistas interessados em compreender os fenómenos sintácticos que constituem as principais diferenças entre o português europeu $(\mathrm{PE})$ e o português do Brasil (PB).

Quem conhece o trabalho de Charlotte Galves sabe já que esta linguista se distingue pela sua fina capacidade de observação dos dados. Na verdade, muitas das principais diferenças subtis entre o PE e $\mathrm{PB}$ foram identificadas durante o percurso de investigação reproduzido neste livro. As várias descrições que a autora nos tem oferecido contribuem para uma caracterização empiricamente adequada dos verdadeiros factores de variação entre as duas gramáticas do português. Esta não é uma questão menor, uma vez que, sem este tipo de trabalho, se corre o risco de fazer generalizações erradas sobre o tipo de variação existente, construindo-se assim hipóteses erradas.

Este livro reflecte ainda outra faceta importante desta linguista: a sistematicidade da sua investigação. Ao longo de 15 anos, Charlotte Galves tem trabalhado sobre hipóteses de trabalho relativas à variação entre PE e PB que colocam o enfoque principal sobre quatro factores: as construções de tópico, o sistema pronominal, o sistema de concordância e a relação entre o estatuto dos elementos pré-verbais e a estrutura da frase. Esta sistematicidade na busca de respostas analíticas que relacionem estes factores sobressai na leitura deste livro. Organizados cronologicamente, os vários capítulos, quando lidos de seguida, quase não parecem textos independentes, dado que existe um encadeamento natural entre eles. De uma forma geral, cada capítulo retoma e aprofunda hipóteses levantadas no capítulo anterior, tentando resolver questões deixadas em aberto. Se bem que pensado de forma a permitir uma leitura independente dos vários capítulos (o que se traduz numa constante repetição de alguns dos conjuntos de dados), este livro pode 
ser perfeitamente lido como um todo e não como uma mera colectânea de ensaios.

Numa altura em que muitos dos estudos em sintaxe se debruçam sobre questões de natureza comparada, sentindo-se uma necessidade de identificar factores de microvariação, o livro de Charlotte Galves é uma ferramenta essencial, mostrando que se deve ter algum cuidado em relacionar línguas aparentemente tão próximas como o PE e o PB. Como a autora mostra, muitas das semelhanças são consequências de sistemas bastante diferentes, não havendo motivo teórico para aparentar estas línguas. A abordagem mais correcta para estabelecer a relação, como a autora faz nos capítulos finais, consiste em procurar a origem histórica comum das duas gramáticas e entender os diferentes caminhos que conduziram à existência da gramática do $\mathrm{PE}$ e da gramática do PB.

\section{Síntese}

No primeiro capítulo, Charlotte Galves faz uma apresentação bastante completa do livro. Este capítulo encontra-se redigido de tal forma que permite ao leitor, desde logo, saber o conceito de gramática a ser utilizado ao longo do livro, o enquadramento teórico das análises propostas, bem como o escopo empírico deste trabalho. A exposição detalhada destas questões torna-se fundamental para se entender qual é o objecto de estudo: as línguas faladas no Brasil e em Portugal e não uma qualquer abstracção mediada por preceitos normativos, que desvirtuariam o objectivo da pesquisa. A primeira síntese feita neste capítulo dos problemas a ser estudados revela desde o início a já referida intuição e fina capacidade de observação da autora para detectar a diferenças entre as duas gramáticas do português. Esta síntese serve também para orientar o leitor na busca de tópicos precisos e permite "contar a história" do percurso de pesquisa. Apesar de a autora enfatizar aparentes contradições nas suas próprias análises, logo neste capítulo introdutório, se torna patente a sistematicidade da linha de investigação da linguista. As tais contradições não são muitas vezes mais do que consequências do próprio desenvolvimento do quadro teórico da sintaxe generativa.

O capítulo 2 oferece uma primeira proposta de análise das diferenças entre PE e PB relativamente à questão do sujeito nulo. A autora descreve as diferenças de comportamento entre os sujeitos nulos referenciais do PE e do PB. Este capítulo reveste-se de grande importância, uma vez que permite problematizar esta questão, mostrando que não é rigoroso dizer simplesmente que o PB deixou de ser uma língua de sujeito nulo. Este trabalho de Charlotte Galves e a sua problematização têm gerado muitas dissertações e artigos que reinterpretam a sua análise. Curiosamente, a ideia de que o pronome em 
PB é um elemento flexional e não um DP em posição de especificador tem sido retomada por vários autores em artigos recentes. A ideia de que existe uma diferença no estatuto categorial dos sujeitos nulos do PE e do PB (aqui expressa como uma oposição entre pro e PRO) é também uma hipótese que tem sido retomada em todos os trabalhos sobre este assunto, ainda que a caracterização exacta do sujeito nulo do PB varie. Finalmente, importa ainda referir que a hipótese avançada neste capítulo de que uma regra de predicação para o estabelecimento de relações de co-referência entre tópicos e elementos pronominais surge aqui como uma proposta que norteará vários estudos que tratam o PB como uma língua orientada para tópico e em que a flexão e tópicos se relacionam. Esta hipótese surgirá recorrentemente nos trabalhos de Charlotte Galves e de muitos outros linguistas que estudam o PB.

O capítulo 3 apresenta uma excelente sistematização das principais diferenças entre o PE e o PB, nomeadamente no que diz respeito ao enfraquecimento da concordância verbal, ao uso e interpretação do pronome ele em posição de sujeito e de objecto directo e ao desaparecimento de se indeterminado. Para além de servir de referência descritiva a quem desejar trabalhar sobre as diferenças entre as duas gramáticas, este capítulo reforça a ideia já discutida no capítulo anterior de que a interpretação dos pronomes e a perda de sujeitos nulos deve ser interpretada, na linha dos trabalhos de Eunice Pontes, mais como uma consequência da orientação para o discurso do que como uma simples consequência do enfraquecimento da concordância, conforme aconteceu na evolução de outras línguas. Também são apontadas algumas diferenças entre dialectos do português brasileiro, no que diz respeito à interpretação de pronomes, um tema que é retomado mais exaustivamente no capítulo seguinte. Um aspecto deste capítulo que merece algum destaque é a consequência metodológica das diferenças apontadas por Charlotte Galves. A autora mostra claramente que uma abordagem meramente superficial de duas línguas aparentemente semelhantes pode ser inconclusiva, se se partir do pressuposto que a variação é necessariamente mínima. No caso específico das formas pronominais, a autora mostra que o PB se aproxima mais de outras línguas orientadas para o discurso do que do PE.

O tema da interpretação dos pronomes é retomado no quarto capítulo, onde se estuda o facto de o pronome ele poder ter uma interpretação reflexiva em PB. Esta construção é interessantíssima, uma vez que permite, como a autora faz, questionar o estatuto desta forma como pronome. Galves apresenta vários argumentos para mostrar que não é possível tratar a forma ele como uma anáfora. A autora propõe uma interessante análise contrastiva entre dialectos do PB e o castelhano, mostrando que, tal como os outros fenómenos discutidos em capítulos anteriores, a interpretação reflexiva do pronome pode ser explicada como um efeito colateral do PB como língua orientada para 
tópico. Assim sendo, a relação que se estabelece entre o pronome e o seu potencial antecedente é uma relação indirecta não de ligação, mas de linking, o que permite relacionar esta construção com outras relações de linking discutidas por Montalbetti. Este capítulo convida a testar a hipótese, tentando saber-se se todos os sujeitos que são possíveis antecedentes de 'pronomes reflexivos' têm necessariamente uma interpretação de tópico.

No capítulo 5, a interpretação dos pronomes é de novo retomada em associação com o papel desempenhado pelas relações de predicação estabelecidas face a um tópico. É estudado neste capítulo o facto de a construção de objecto nulo em PB, ao contrário do que acontece em PE, não ser sensível a ilhas. Charlotte Galves defende que o objecto nulo é identificado como pro, o que explicaria a insensibilidade a contextos-ilha. Contudo, como a autora nota, há dados que se revelam contraditórios face a esta hipótese. Nomeadamente, os contextos em que o objecto nulo não apresenta um comportamento idêntico ao pronome lexical, não podendo ser ligado por um antecedente não-local. Para resolver este problema, a autora, assumindo várias propostas sobre identificação de papéis temáticos, legitimação de categorias vazias e as diferentes posições que o sujeito pode ocupar na frase propõe que as diferentes possibilidades de interpretação do objecto nulo decorrem não de propriedades do mesmo, mas de questões gerais de interpretação de categorias vazias e da estrutura da frase em PB. São feitas algumas propostas sobre a hierarquização das categorias funcionais e sobre o local ocupado pelos diferentes sujeitos, relacionando-se a construção de objecto nulo com os objectos das estruturas-tough. Este capítulo é talvez o mais ousado em termos da novidade das propostas, deixando o leitor com vontade de explorar muitas das suas consequências para outros aspectos da sintaxe do PB. Destas, destaca-se a necessidade de testar as consequências das assunções feitas pela autora sobre a interpretação e posição de pro para o debate sobre o estatuto do sujeito nulo em PB. Ao escolher uma abordagem temática para a solução destes problemas, a autora consegue fazer uma análise geral da estrutura do PB, mas corre o risco de perder a capacidade de restringir as propostas a esta língua. Ficamos assim com vontade de determinar por que motivo haverá questões de natureza temática tão particulares a uma determinada gramática. Importa, contudo, realçar que, à data da escrita deste artigo (1989), não era ainda frequente a necessidade de restringir ao mínimo indispensável as fontes de variação interlinguística. Trabalhos mais recentes, como Costa e Duarte (2001) tentam derivar as diferenças em termos de contexto-ilha, propondo que o objecto nulo não é necessariamente a mesma categoria em todos os contextos.

A questão do sujeito nulo e do papel desempenhado por Agr e pelo movimento do verbo é discutida no sexto capítulo. Este capítulo reveste-se 
de grande importância, uma vez que mostra a novidade das hipóteses de Galves face a várias propostas feitas independentemente na literatura vários anos mais tarde e assumidas agora por muitos sintacticistas. A autora discute o estatuto de Agr em PB, mostrando que a concordância morfológica fraca não obriga a que não exista movimento do verbo. É proposta uma revisão das propostas de Roberts (1993), adiantando-se vários dos aspectos discutidos mais tarde em trabalhos de Rohrbacher e de Vikner sobre a importância do traço pessoa dentro do sistema de concordância. A autora propõe ainda uma caracterização do movimento de verbo em PB como uma instância de movimento de V-para-T e não V-para-Agr. Surge também como inovador o facto de ser proposto que a estrutura funcional da frase é sujeita a variação interlinguística e a caracterização do papel de $\mathrm{T}$ em termos da dicotomia forte/fraco e do seu papel como categoria com capacidade para atrair o verbo. Este capítulo oferece ainda uma discussão bastante detalhada do comportamento dos quantificadores flutuantes. Por vezes os dados do PE discutidos não são muito precisos, embora a autora se baseie noutros autores para a descrição desta língua. Lamentavelmente, essa descrição compromete algumas das conclusões tiradas sobre eventuais diferenças entre PE e PB. Não obstante este problema, este capítulo é de grande riqueza de conteúdo, sobretudo tendo-se em conta a novidade das propostas na altura em que foi escrito.

Uma das diferenças entre PE e PB mais saliente é a existência de ênclise generalizada apenas em PE. No sétimo capítulo, esta questão é tratada de uma forma bastante detalhada. Em vez de, como fazem alguns autores, se restringir a discutir o contraste entre próclise e ênclise, a autora mostra que o comportamento dos clíticos em PB não é uniforme, explorando através do recurso a corpora, a frequência e distribuição dos vários clíticos. Na sequência da análise desenvolvida no capítulo anterior, é proposto que a diferente colocação dos pronomes em PB é uma consequência do enfraquecimento da concordância nesta língua. Este facto, combinado com a hipótese sobre movimento do verbo e algumas considerações sobre as condições necessárias para a verificação de caso derivam os padrões de frequência e a posição proclítica observadas nos corpora. Teremos de esperar ainda alguns capítulos até descobrir as assunções da autora relativamente ao PE. O leitor português tentará de imediato descobrir como é derivada a diferença entre as duas gramáticas. São dadas várias pistas, que levantam várias questões. Por exemplo, existe alguma evidência para dizer que o alvo do movimento do verbo nas duas línguas é o mesmo, conforme defendido em Costa e Galves (2000). Ainda assim, é deixado claro um facto que a grande parte dos autores considera unânime e cuja sustentabilidade deve muito ao trabalho desenvolvido pela autora deste livro: a próclise em $\mathrm{PB}$ não é idêntica à próclise 
noutras línguas românicas.

O tema do capítulo anterior é reinterpretado à luz de propostas minimalistas no capítulo 8. Neste capítulo, a autora tenta explicar por que motivo o pronome ele em $\mathrm{PB}$, apesar de aparentemente ser um pronome forte, exibe propriedades que o aproximam dos pronomes fracos, no âmbito da tipologia proposta de Cardinalleti e Starke (1994). Retomando os argumentos sobre a natureza da categoria Agr em PB, Charlotte Galves propõe que o comportamento deste pronome, bem como a inexistência do pronome acusativo o/a, derivam do facto de AgrO ser forte em PB, enquanto AgrS é fraco (não assumindo, contudo, a existência destas categorias como unidades autónomas). Contribui também para a oposição entre o comportamento dos pronomes em PE e PB o papel desempenhado pelo traço [pessoa] e as possibilidades de interpretação decorrentes da estrutura da frase. Este capítulo propõe uma análise semelhante aos anteriores, sendo patente o esforço de adaptar propostas anteriores ao modelo minimalista. São deixadas em aberto implícita ou explicitamente várias questões que convidam a aprofundar as propostas feitas. De entre essas questões, destaco: a) haverá argumentos posicionais fortes para assumir que o pronome ele não ocupa a sua posição de base?; b) a hipótese de que Agr em T é fraco e Agr em vé forte são baseadas em argumentos morfológicos e posicionais respectivamente. Será possível encontrar evidência morfológica para a hipótese de que Agr em $v$ é forte?; c) existirão pronomes fortes em PB? Como diferenciá-los do pronome ele em posição de objecto?; d) são feitas propostas que apontam para uma diferença entre ele em posição de sujeito e de objecto. Que outros argumentos podem ser usados para favorecer esta hipótese?

O papel desempenhado por Agr é uma constante nos ensaios recolhidos neste livro. No capítulo 9, é feita uma revisão da hipótese de Raposo (1987) sobre a distribuição dos infinitivos flexionados em PE. Charlotte Galves levanta vários problemas empíricos para a análise de Raposo e propõe uma simplificação da análise, assumindo, na esteira de vários trabalhos de Rizzi, que Agr pode ser associado a diferentes categorias funcionais. De acordo com a autora, assumir que, em $\mathrm{PE}$, Agr pode ser associado à categoria $\mathrm{C}$ explica a distribuição dos infinitivos flexionados, apresentando simultaneamente uma eventual solução para a posição enclítica dos pronomes, se se assumir que a ênclise é uma consequência de movimento de $\mathrm{V}$ para uma categoria mais alta do que a posição que o clítico ocupa, na linha de Kayne (1991) e Martins (1994) para o PE. Testar esta hipótese abre também novas perspectivas de investigação. Por exemplo, torna-se necessário, tal como no capítulo anterior, saber que critérios morfológicos permitem afirmar a presença de Agr em C (sobretudo tendo em conta a existência de complementadores com marcas explícitas de concordância em línguas como 
o Flamengo Ocidental). É também necessário avaliar as consequências desta análise para uma comparação com as línguas para as quais Rizzi propõe a existência de Agr em C e que não possuem infinitivo flexionado.

A existência de Agr em C em PE é desenvolvida no capítulo seguinte, conforme já fora de certa forma prometido no capítulo anterior, para derivar a colocação enclítica dos pronomes nesta gramática. Charlotte Galves assume que o PE tem algumas características que o aproximam de línguas V2, assumindo que em frases SVO o verbo se desloca até Ce o sujeito até Spec,CP. Este tipo de análise é bastante controverso, conforme discutido em trabalhos como Ambar (1992), Duarte (1987) e Costa (1998). Todos estes trabalhos apontam argumentos empíricos contra esta hipótese. Contudo, a argumentação desenvolvida pela autora é, de novo, coerente com o seu trabalho anterior e explora uma linha de investigação iniciada sobretudo com o trabalho de Kayne (1991), de acordo com a qual a posição dos clíticos é uma consequência da posição ocupada pelo verbo. Ainda que haja argumentos contraditórios (patentes até na hipótese formulada em Costa e Galves 2000, de acordo com a qual o movimento do verbo nas duas gramáticas não é distinto, o que mostra bem a consciência da autora sobre a necessidade de considerar várias hipóteses), Charlotte Galves contribui de uma forma eficiente para este debate, levantando as questões pertinentes e propondo soluções para os aspectos mais problemáticos da sua proposta, como a existência de próclise em contextos interrogativos em que o verbo se move para $\mathrm{C}$.

Alguns dos problemas apontados relativamente ao capítulo anterior são abordados e parcialmente resolvidos nos dois últimos capítulos. Investigando o bem conhecido padrão de mudança de colocação dos clíticos que ocorreu na passagem do português clássico para o $\mathrm{PE}$ contemporâneo, a autora propõe que a composição de traços de $\mathrm{C}$ foi alterada. Em consequência, os elementos pré-verbais em PE não ocupam necessariamente uma posição periférica à categoria funcional mais alta, como é proposto que acontecia em português clássico. Para compatibilizar as suas hipóteses sobre movimento de verbo com a posição dos clíticos, Charlotte Galves apresenta uma hipótese, a meu ver, interessantíssima: a de que os clíticos em ênclise e em próclise correspondem a realidades morfológicas diferentes. Assim, é defendido que a sequência $\mathrm{Cl}+\mathrm{V}$ é um produto da sintaxe, enquanto a sequência $\mathrm{V}+\mathrm{Cl}$ é resultado de uma operação morfológica. Esta hipótese, inovadora à data da publicação do artigo, é bastante aliciante, uma vez que é perfeitamente natural à luz de assunções actuais feitas no quadro da Morfologia Distribuída (Halle e Marantz 1993). Além disso, as consequências desta proposta são compatíveis com os resultados a que outros autores chegaram para a estrutura da frase em PE. No capítulo final, a proposta sobre o que condicionou a mudança do português clássico para as duas gramáticas do português é 
aprofundada, avaliando-se as consequências das assunções feitas para explicar não só a sintaxe dos pronomes, como a posição dos sujeitos e as várias manifestações do fenómeno de topicalização. Claramente, ficam por responder algumas questões relativas ao que desencadeou a mudança linguística. A autora reconhece este problema e avança algumas ideias sobre o que tem norteado o interessante projecto de investigação que dirige já há alguns anos.

\section{REFERÊNCIAS BIBLIOGRÁFICAS}

Cardinaletti, Anna \& Starke, Michal. 1994. The Typology of Structural Deficiency. Ms. University of Venice, University of Geneva.

Costa, João \& Charlotte GaLves. 2000. External subjects in two varieties of Portuguese. A publicar em Selected proceedings of Going Romance 2000, Johns Benjamins, Amsterdam

Costa, João \& DuARte, Inês. 2001. Objectos nulos em debate. In: Razões e emoção. Miscelânea de estudos em homenagem a Maria Helena Mateus. Edição on-line

Halle, Morris \& Alec, Marantz. 1993. 'Distributed Morphology and the Pieces of Inflection.' In: The View from Building 20. ed. Kenneth Hale and S. Jay Keyser. Cambridge: MIT Press: 111-176.

KaYne, Richard. 1991. Romance Clitics, Verb Movement, and PRO. Linguistic Inquiry, 22: 647-686.

Martins, Ana Maria. 1994. Clíticos na História do Português. Tese de Doutoramento, Univ. Lisboa

Raposo, Eduardo. 1987. Case Theory and Infl-to-Comp: The inflected infinitive in European Portuguese. Linguistic Inquiry, 18: 85-109.

RoBERTs, Ian. 1993. Verbs and diachronic syntax. Studies in natural language and linguistic theory. Kluwer, Dordrecht. 